\title{
THE USE OF SHORT ACTING MUSCLE RELAXING DRUGS IN OBSTETRICAL ANAESTHESIA*
}

\author{
J. W. Dennis, m.d. and John J. Carroll, m.D.* *
}

IT is now over twelve years since Dr. Harold Griffith (1) first introduced the use of muscle relaxants into the field of anaesthesia. Since that time, they have been widely used and much has been written about them in relation to surgical anaesthesia. However, this is not the case regarding obstetrical anaesthesia, where the advantages of these drugs seem to have been overlooked by most anaesthetists.

Over the past three years the various members of our group have used muscle relaxants combined with light general anaesthesia for 591 deliveries.

The first muscle relaxant chosen for study was Syncurine or decamethonium bromide. This drug was chosen because of its effectiveness in producing good muscular relaxation and, compared to d-tubo-curare, for its relatively short action. Besides being the first relaxant studied, it has become with us the most popular one for obstetrical anaesthesia, for reasons we shall see later.

Syncurine has now been given to 451 obstetrical patients, of which approximately three-quarters were primiparae. The reason for the high proportion of primiparae is that these are the cases that usually present more difficulty at time of delivery, and are the ones where relaxation is more difficult to obtain.

In regard to the dosage used, in this series it has varied from one to five milligrams in a single injection. In some cases, such as in twin deliveries, we have given a second injection a short time after the first, and in this manner we have reached a total dosage of seven milligrams within a period of twenty minutes. Early in the series we tended to use smaller doses, such as two, and two and a half milligrams, but lately we seldom go below three and often use four or five milligrams.

The anaesthetic used is a mixture of nitrous oxide and oxygen given in approximately 75-25 concentration. We have found that by increasing the dosage of Syncurine to three milligrams or more, we are often able to carry the patient through the entire procedure, including the repair of the episiotomy, without resorting to a stronger agent such as cyclopropiane. There seems to be a synergistic action between Syncurine and nitrous oxide which enables one to do this. We feel it is an advantage to be able to avoid using cyclopropane, as this drug is depressing to the baby if given for more then ten minutes before delivery. If we can avoid it the patients are also less lisely to vomit, and this is much appreciated by them and commented upon when we visit them a day or two later.

The patients who received Syncurine can be divided into three groups:

1. The first group is composed of those cases where the baby is a vertex

*Presented at the Annual Meeting, Canadian Anaesthetsts' Society, June 14, 1954.

- Department of Anaesthesia of Grace Hospital, Vancouver, BC, and the Burnaby Hospital, Burnaby, B.C.

Canad. Anaes. Soc. J., vol. 1, no. 2, Oct., 1954 
presentation and the obstetrician wishes to proceed with a forceps delivery. These patients, who have been receiving a mixture of $75 \%$ nitrous oxide and $25 \%$ oxygen with therr pains, are then given the selected dose of Syncurine intravenously. In two or three minutes they will be completely relaxed and the obstetrician can proceed with the delivery. This group constitutes over $90 \%$ of the total cases.

2. The second group are the breech deliveries where the relaxant is given to facllitate delivery of the after-coming head. Here the injection of Syncurine must be tmed very accurately to ensure that there is maximum relaxation at the time the head is being delivered.

3 The third group comprises those cases which are progressing, very rapidly and where there is danger that the baby will precipitate. The relaxant stops all voluntary pushing by the mother, so the head can be delivered gradually, avoiding undue damage to either the baby's head or the mother's peririeum.

Now let us consider the effect of Syncurine on the maternal respiration. There is usually an apnoea of four to eight minutes depending on the amount of Syncurme given. With smaller doses such as one or two milligrams, there may be merely respiratory depression, but with the larger doses there is usually an apnoea. The longest recorded in cur series was eighteen minutes. Durmg this time the patient is adequately oxygenated by manual compression of the breathing bag. It is most important that the mother receives a good supply of oxygen at all tmes If the controlled respiration is carried on with extreme vigor the period of apnoea can be prolonged further.

The next and very important consideration is the effect on the baby. The fear that there would be placental transmission of the relaxant to the baby has made many people hesitate to use them in obstetrical cases. From this series it appears to be quite definite that Syncurine is not transmitted across the placenta in any effective concentration. In this series $94 \%$ of the babies recuired no resuscitation. Of the remainder, about half had an obvious cause for tzerr difficulty, such as the umbilical cord being pulled tight about the baby's neck. Auscultation of the maternal abdomen in these cases often reveals a slow fetal heart rate prior to delivery. About $3 \%$ of babies required resuscitation for no apparent reason. This figure is extremely low, and we feel this amount of difficulty would be encountered in any similar series, regardless of anaesthetic agents.

The question of placental transmission of Syncurine is very interesting and various anaesthetists have held divergent views on this subject. Ellerker (2), writng in the British Medical Journal, felt that it did cross the placenta, although at a slower rate than d-tubo-curare, and that it caused depression in some babies. On the other hand, Organe (3), on the basis of his clinucal expenence, felt it was quite safe. Dr. Young (4) did some interesting experıments using Syncurine on pregnant rabbits and gumea pigs, wherem she definitely showed that the placenta was an effective barrel to the transmission of the Syncurine. The majority of those writing on Syncurine in recent years feel the placenta is a barrier to its transmission. We concur with this viewpoint.

Another advantage of Syncurme is that the obstetrician is nearly always able to deliver the placenta without delay. Thrs would indicate these was no de- 
iression of uterine tone by the Syncurine, and the uterus is able to respond to .re injection of pitocin which is usually given immediately following the birth of the baby. This is attributed to the fact that the mother is being carried in a ighter plane of ancesthesia so that the uterine contractions are not slowed down as they would be sy any of the more powerful agents such as ether or cyclopropane. In their article on this subject, Austin and Mering (5) state that Syncurine does not interfere with uterine contractions.

The incidence of episiotomies was not reduced greatly, as $72 \%$ of the cases required them. However, the size of the episiotomies was markedly reduced. In discussing this matter with the obstetricians, their impression was that they were often able to deliver the baby using a much smaller episiotomy than would otherwise have been required if a relaxant had not been used.

When the succinylcholine group of relaxants appeared we decided to give them a trial to learn if they had any advantages over Syncurine. To date we have used this group on 140 cases. The drugs studied were Anectine and Winthrop 7907, which are both the chloride, anc Brevidil which is the bromide. All forms are equally satisfactory, but the dosage of the chloride and the bromide differ slightly in relation to the proportion of the active cation in the two compounds.

Of the 140 cases, only 37 were multiparae. Forceps were used in $80 \%$ of the cases. The succinylcholine relaxants were given in the same manner as that described for Syncurine and excellent relaxation was achieved.

There are some differences noted in this series as compared to the previous one:

1. The onset of relaxation is quicker than with Syncurine. Whereas with Syncurine it takes three or four minutes to get good relaxation, it only takes a minute with the succinylcholine group. This is useful when you require immediate relaxation as for the delivery of the head in breech presentations.

2. The period of relaxation and of maternal apnoea is shorter with the succinylcholine group. Most patients breathe adequately in three or four minutes, and this is distinctly advantageous where there is any difficulty with the resuscitation of the baby. We are also responsible for the resuscitation of the child, and so whatever measures are necessary can be instituted immediately.

3. If there is a large episiotomy, or if the obstetrician is slow with his repair, it is usual y necessary to supplement the nitrous oxide with some more potent agent, suc. as cyclopropane or ether. These agents increase the incidence of vomiting. Therefore recovery is not as pleasant as when only Syncurine and nitrous oxide are required.

Again with this series of relaxants, resuscitation of the babies presented nodifficulty. In only seven out of the 140 cases were moderate measures required, and in four of these there were obvious causes for the de aression, such as an excess of ojiate given to the mother, or a tizht cord around tue baby's neck. Only three of tue 140 cases required modera:e resuscitation where there was no ap sarent cause; this we feel is an acceptable percentage.

From this series it appears that the placenta is also an effective barrier to the passage of the succinylcholine group of relaxants. It may be that they are de- 
toxified by the pseudo-cholinesterases in the mother's body before they reach the placenta.

The dosage in this series has ranged from 10 to 70 milligrams, with an average dose of 30 to $\mathbf{4 0}$ milligrams. Except for a few cases where very small doses were given, all the patients developed apnoea. As mentioned previously, the period of apnoea with this group of drugs is quite short, and lasts only two or three minutes. Assisted or controlled respiration was instituted wherever necessary to make certain the patient received an ample supply of oxygen at all times.

On the basis of this series of 591 deliveries we feel that the muscle relaxants offer advantages to all concerned. These are-

1. Advantages to the baby. By the addition of muscle relaxants much lighter general anaesthesia can be given to the mother and so the baby receives proportionately less anaesthetic and is less depressed. Also by having the muscles of the mother's perineum completely relaxed, much strain and trauma to the baby can be removed.

2. Advantages to the mother. With the complete muscular relaxation afforded by these drugs, smaller episiotomies have proved to be adequate and extension of episiotomies by tears have become infrequent. As a result less damage has been done to the perineum, and this is obvious at the time of the mother's sixweek checkup. The decreased incldence of vomiting is much appreciated and is another advantage of this technique.

3. Advantages to the obstetrician. The completely relaxed musculature faclitates operative jrocedures and enables the obstetrician to deliver the baby deliberately and witiout trauma.

4. Advantages to the anaesthetist Obstetrical patients are often poorly premedicated, and so are much more likely to develop complications such as excess salivation and laryngeal spasm. The addition of muscle relaxants tends to prevent such complications and makes the anaesthetic much smoother.

In conclusion we feel that muscle relaxants are a very definite asset in the field of obstetncal anaesthesia. They should not be used by untrained personnel, but in the hands of a trained anaesthetist they offer many advantages to the mother, baby and obstetrical team.

\section{SUMMARY}

Decamethonium Bromide and Succinyl Choline have been used in combination with nutrous oxide anaesthesia to produce muscular relaxation for the vaginal delivery of 591 obstetrical patients. There has been no evidence of placental transmission of these drugs to the baby. The use of these drugs has made possible the employment of lighter general anaesthesia, smaller episiotomies, and control of precipitate delivery. Advantages have accrued to the baby, and the mother, and to the obstetrician and the anaesthetist.

\section{RÉSUMÉ}

Le Bromide de Decamethonium et le Succinyl Choline ont été employés en combinaison avec l'anesthésie à loxyde nıtreux pour produire le relâchement musculaire pour l'accouchement vaginal de 591 patients. Il n'y a pas eu in- 
dication de transmission placentale de ces drozues au bébé. Ces drogues ont rendu possible l'emploi d'une anesthésie généra_e plus légère, des incisions plus légères de la vulve, et le contrôle des précipités d'accouc_ıement. Les avantages ont augmentés en nombre pour le bébé, la mère, l'accoucheur et l'anesthésiste.

\section{ACKNOWLEDGEMENTS}

We wish to thank the other members of our $\xi$ roup, Drs. P. B. Percheson, J. A. McNab and A. C. Blair, for their assistance in tuis work, and the obstetricians at Grace and Burnaby Hospitals for their co-operation in compiling this series. Thanks are also due Burroughs Wellcome, Poulenc, and Winthorp-Stearns, for their generous supply of the various drugs used.

\section{REFERENCES}

1. Grufritr, H. R. and Johnston, G. E. The Use of Curare in General AnaesthesiaAnaesthesiolozy 3.418-420 (July) 1942.

2. ELLerker, A. A. British Medical Journal 2.3981950.

3. Organe, G. Lancet 1:773 1949

4. Young, M. Lancet 1:1052 1949 .

5. Austns, B. R. and MernvG, T. W. American Journal of Obstetrics and Gynaecology, 62:143 1951. 